\title{
Healthy maternal bonding as a resilience factor for depressive disorder
}

\author{
Agnes M. Miranda ${ }^{1}$, Claudio N. Soares ${ }^{2}$, Maira L. Moraes ${ }^{1}$,Victor Fossaluza ${ }^{3}$, Paula M. Serafim ${ }^{1}$ \\ and Marcelo F. Mello ${ }^{1}$ \\ 1- Universidade Federal de São Paulo, São Paulo, SP, Brazil \\ 2- McMaster University, Hamilton, Ontario, Canada \\ 3- Universidade de São Paulo, São Paulo, SP, Brazil
}

\begin{abstract}
Introduction: Depressive disorders (DDs) are very prevalent disorders particularly in women, a high-risk gender group. Determining the risk and protective factors associated with the development of DDs is fundamental to planning preventive and therapeutic strategies. In this study, we evaluated the correlations between healthy maternal attachment and the development of DDs in adulthood. Methods: We evaluated 52 women at 6 months to 1 year after premature childbirth at Maternidade Vila Nova Cachoeirinha. They were evaluated using the following instruments: Brazilian Criteria of Economic Classification,Parental Bonding Inventory (PBI),Center for Epidemiologic Studies Depression Scale (CES-D), and Edinburgh Postnatal Depression Scale (EPDS). Cut-off scores on the CES-D and EPDS were used to classifythe subjects as currently having a DD or having probable postpartum disorder (PPD) after childbirth. Multiple logistic regression was used to evaluate the risk factors associated with DDs. Results: We found that $49.1 \%$ of the sample had a current depressive episode, and $73.6 \%$ had probable PPD. Based on logistic regression, current depression (odds ratio $=1.092$ [confidence interval: $1.005 ; 1.186$ ]), and a PPD (odds ratio $=1.108$ [confidence interval: $1.011 ; 1.21$ ]) were negatively correlated with affective maternal relationships. Conclusions: Women who reported healthy attachment with their mothers did not develop DDs when faced with stressful situations such as premature childbirth. Keywords: mood disorders; postpartum; women; families; other psychological issues.
\end{abstract}

Received 8 December 2011; received in revised form 14 June 2012; accepted 14 June 2012. Available online 29 June 2012.

\section{Introduction}

Depressive disorders (DDs) are highly prevalent (Murray \& Lopez, 1997) in the general population, particularly in women, a high-risk gender group. Major depression causes a significant burden to society (Murray \& Lopez, 1997). Determining the risk and resilience factors associated with the development of DDs will help build effective preventive and therapeutic strategies.

The role of functional maternal attachment in mental health development in adulthood has been extensively studied psychoanalytically, but little empirical data on this topic can be found. Lima, Mello,

Agnes M. Miranda, Maira L. Moraes, Paula M. Serafim, and Marcelo F. Mello, PROVE Institute, Program for Research and Treatment of Violence, Department of Psychiatry, Federal University of Sao Paulo, Brazil. Claudio N. Soares, Department of Psychiatry \& Behavioral Neurosciences, McMaster University, Hamilton, Ontario, Canada. Victor Fossaluza, (IME-USP) Institute of Mathematics and Statistics, University of São Paulo (Instituto de Matemática e Estatística da Universidade de São Paulo). Correspondence regarding this article should be directed to: Agnes M. Miranda, Rua Botucatu, 431 São Paulo, SP 04023-061, Brazil.Phone/Fax: +5511 50822860. E-mail: agnesmiranda@uol.com.br and Mari (2010) reviewed the scientific literature for the role of early parental bonding in the development of psychiatric symptoms in adulthood. These authors found only studies that correlated depressive disorders with parental bonding. Ward, Lee, and Pola (2006) found statistically significant positive correlations between psychopathology and dysfunctional parental attachment. Fortuna and Roisman (2008) also found positive associations between parental neglect and symptoms of depression in adulthood. Stansfeld, Head, Bartley, andFonagy (2008) retrospectively evaluated 7,279 subjects and found that a high level of parental warmth was highly correlated with decreased risk of insecure attachment styles associated with the development of psychiatric disorders in adulthood, mainly DDs. O'Connell (2008) examined the relationship between attachment and adulthood well-being outcomes in a sample of subjects who had severely mentally ill mothers. Half of the subjects had a diagnosis of depression, andthe subjects who reported family issues and dysfunctional parental styles had many more diagnoses of major depression.

Different mother/child relationship styles differentially affect the mental health of their siblings 
during adulthood (Rikhye et al., 2008). Enns, Cox, and Clara (2002) replicated this finding, showing that both excessive and a lack of parental care increased the incidence of mental disorders and dysfunctional behavior in siblings when they reached adulthood. Furthermore, a greater correlation was found between the mother's behavior and sibling psychopathology compared with the father's behavior. Hand, Ito, Tsuda, Ohsawa, and Ogawa (2009) reported that a familiar environment not only influences the development of DDs but is also related to chronicity. The affective parental relationship is a necessary condition to promote the independence of children as they develop. Careful but encouraging parents are crucial for the emotional development of children. In contrast, unhealthy parental practices that are indifferent, negligent, or overprotective are strongly related to the development of DDs in adulthood (Grotmol et al., 2010).

Parker, Hadzi-Pavlovic, Greenwald, and Weissman (1995) also showed that an overprotective or controlling mother increased the risk of developing DDs in siblings in adulthood. These authors hypothesized that these types of relationships restricted the development of a sense of self-esteem, impairing the process of social competence. According to Restiffo, Akse, Guzman, Benjamins, and Dick (2009), parental bonding is the best predictor of low self-esteem and low autonomy, factors often associated with DDs. The quality of parental bonding is fundamental to determining the way in which children will evaluate themselves and, consequently, the way they will construct future relationships and social choices (Campos, Besser, \& Blatt, 2010).

The present study evaluated a group at high-risk for developing DDs (i.e., women with lower socioeconomic status who recently experienced a premature birth). These women were assessed at least 6 months and 1 year after delivery to avoid postpartum blues or PPD that remitted spontaneously after this period. The present analysis examined the correlations between the presence of DDs and the different types of maternal bonding that these women had with their mothers during childhood and adolescence.

\section{Materials and Methods \\ Sample}

All subjects were selected from the Maternidade Vila Nova Cachoeirinha outpatient clinic. Maternidade Vila Nova Cachoeirinha is a 147 -bed public hospital and referral center for pregnancy and delivery in highrisk newborns in São Paulo. Annually, up to 6,000 childbirths or C-sections occur at this hospital.

All of the mothers who had a premature delivery who were registered at Maternidade Vila Nova Cachoeirinha during a period of 6 months to 1 year after delivery and whose children were registered at premature outpatient clinics were contacted by mail or phone and invited to participate in the study. All of the women who agreed to participate were interviewed, and those who met the inclusion criteria and were not ineligible based on the exclusion criterion were included.

The inclusion criteria included the following: (1) had a preterm childbirth within 6 to 12 months prior to study enrollment at Maternidade Vila Nova Cachoeirinha and (2) signed informed consent previously approved by Universidade Federal de São Paulo and the Maternidade Vila Nova Cachoeirinha Institutional Review Boards. The exclusion criterion was the presence of cognitive impairment or other factors that could affect the ability to provide informed consent.

\section{Instruments}

Brazilian Criteria of Economic Classification (Associação Brasileira de Empresas de Pesquisa, 2003, 2007). The Brazilian Association of Research Companies developed a family classification questionnaire to determine socioeconomic classes according to a family's purchasing power. The instrument is based on the number of household appliances, existence of private bathrooms inside or outside the dwelling, educational level of the head of the household, and number of household employees who work at least 5 days per week. Total scores were used to determine the socioeconomic status of the family (low: 0-16; middle-low: 17-34). The most recent survey showed that $46 \%$ of the Brazilian population belonged to class $\mathrm{C}$ and $19.5 \%$ belonged to class $\mathrm{D}$. Of the families who lived in São Paulo, $45 \%$ belonged to class C and 16\% belonged to class $\mathrm{D}$.

Parental Bonding Inventory (PBI; Parker, 1989). The PBI is a self-report Likert-type instrument with 25 questions related to the subject's father and mother. The subjects answer how a particular behavior was similar to their parents' behavior until they were 16 years old. The instrument measures the following two dimensions: (1) care and overprotection and (2) encouragement of independence and autonomy. The PBI was adapted to Portuguese by Hauck et al. (2006). One way to use the PBI to analyze parental bonding is by classifying the results of the interaction of both dimensions as the broad parental styles of "optimal bonding" (i.e., high care and low overprotection), "affectionless control" (i.e., low care and high overprotection), "affectionate constraint" (i.e., high care and high overprotection), and "absent or weak bonding" (i.e., low care and low overprotection). The cut-off scores for high and low "care" and "protection"are based on validation studies (Parker, 1983, 1989). Based on the means of these studies, the suggested cut-off care and protection scores are 27.0 and 13.5, respectively, for mothers and 24.0 and 12.5, respectively, for fathers (Parker, 1983). The present study evaluated the PBI for mothers.

Center for Epidemiologic Studies Depression Scale (CES-D; Radloff, 1977). The CES-D is a short selfreport scale designed to measure depressive symptoms in the general population. It is widely used worldwide and has very high internal consistency and adequate test-retest reliability. Response categories indicate the 
frequency of occurrence of each item and are scored on a 4-point scale that ranges from 0 to 3 . The total score can range from 0 to 60 . A score of 16 or higher has been extensively used as the cut-off point for high depressive symptoms.

Edinburgh Postnatal Depression Scale (EPDS). The EPDS is a validated instrument developed specifically to identify women who experience PPD (Cox, Holden, \& Sagovsky, 1987). It is a self-administered, 10-item scale with great acceptability among healthcare professionals and researchers, especially for screening and identification of potential cases of depression (Ruschi, Sun, Mattar, Chambô Filho, Zandonade, \& Lima, 2007). The clinical and epidemiological value of the scale has been confirmed by several validation studies conducted in various countries, with both sensitivity and specificity that vary between $70 \%$ and $85 \%$. It has been validated for Portuguese (Santos et al., 2007). The cut-off point for screening PPD ( $\geq 10)$ demonstrates $82.6 \%$ (75.3-89.9\%) sensitivity and $65.4 \%(59.8-71.1 \%)$ specificity. For moderate-to-severe cases, the best cut-off point was $\geq 11$, with $83.8 \%$ (73.4-91.3\%) sensitivity and 74.7\% (69.4$79.5 \%$ ) specificity. For diagnosis, the EPDS was valid only for the prevalence of PPD in the $20-25 \%$ range, with $60 \%$ positive predictive value for the $\geq 13$ cut-off point (59.5\% sensitivity and $88.4 \%$ specificity). Santos et al. (2007) showed that the EPDS should be interpreted according to the needs of each study. We used 12 as the cut-off point to evaluate PPD in the high-risk group.

\section{Statistical analysis}

All data were transferred to an Excel database and the $\mathrm{R}$ program ( $\mathrm{R}$ Development Core Team,
2008). Subjects were categorized as having current depression if they scored 16 or higher on the CES-D and had probable PPD if they scored 12 or higher on the EPDS. To verify the influence of six variables on the presence of each category (PPD and current depression), we used a logistic regression model.The six variables included in the initial model were PBI affect, PBI control, PBI total score, socioeconomic class, present depression, and probable PPD. This model allowed the calculation of the chances that a patient with determined characteristics had a positive answer. The adopted level of significance was 5\%.

\section{Results}

Of the 53 women we contacted, only one woman whose baby died refused to participate. All women included in the study met the inclusion and exclusion criteria. The participants' sociodemographic and clinical characteristics are shown in Table 1. Overall, the sample was representative of young adults from classes $\mathrm{C}$ and $\mathrm{D}$ who live in poor neighborhoods in São Paulo. They were evaluated onan average of 6-7 months after childbirth. Almost 70\% had probable PPD and 46.1\% were still symptomatic at the time of their evaluation. None of the women received any treatment prior to our evaluation (Table 1).

The first logistic regression that used PPD as a dependent variable showed a significant negative correlation in which having an affective maternal relationship reduced the likelihood of developing PPD. An odds ratio of less than 1.00 also indicates that women who had more affective mothers were less likely to have PPD (Table 2).

Table 1. Clinical and sociodemographic characteristics of the study subjects

\begin{tabular}{lc}
\hline Variable & Value $(n=\mathbf{5 2})$ \\
\hline Age in years (mean \pm sd) & $28.8 \pm 8.1$ \\
Time after childbirth in weeks (mean $\pm \mathrm{sd})$ & $26.3 \pm 7.6$ \\
Socioeconomic class (\%) & \\
A & $1(1.9 \%)$ \\
B & $7(13.4 \%)$ \\
C & $35(67.3 \%)$ \\
D & $9(17.3 \%)$ \\
Edinburgh Puerperal Depression Scale (mean \pm sd) & $16.7 \pm 6.7$ \\
Post-Partum Depression (\% EPDS score $\geq 12)$ & $36(69.2 \%)$ \\
Center for Epidemiologic Studies Depression Scale (mean $\pm \mathrm{sd})$ & $17 \pm 5.5$ \\
Current Depression $(\%$ CES-D score $\geq 16)$ & $24(46.1 \%)$ \\
\hline
\end{tabular}

Table 2. Logistic regression model: presence of PPD (dependent variable)

\begin{tabular}{lccccc}
\hline & Coefficient & S. E. & OR & $\mathbf{9 5 \%}$ CI & $p$ value \\
\hline PBI Affect. Mother & .102 & .047 & 1.11 & $1.01-1.21$ & $.028^{*}$ \\
PBI Control. Mother & -.018 & .037 & .98 & $.91-1.06$ & .625 \\
Age & .019 & 0.32 & 1.02 & $.96-1.08$ & .566 \\
\hline
\end{tabular}

PPD, postpartum depression; PBI, Parental Bonding Inventory; OR, odds ratio; CI, confidence interval; SE, standard error..

*Statistically significant.

Variables entered on step: age, PBI affect. Mother; PBI control.Mother. 
Table 3. Logistic regression model: current depression

\begin{tabular}{lccccc}
\hline & Coefficient & S. E. & OR & $\mathbf{9 5 \%}$ CI & $p$ value \\
\hline PBI Affect. Mother & .088 & .032 & 1.09 & $1.01-1.19$ & $.039^{*}$ \\
PBI Control. Mother & -.006 & .035 & .99 & $.93-1.06$ & .862 \\
Age & .016 & 0.32 & 1.02 & $.95-1.08$ & .616 \\
\hline
\end{tabular}

PPD, postpartum depression, PBI, Parental Bonding Inventory; OR, odds ratio; CI, confidence interval; SE, standard error..

*Statistically significant.

Variables entered on step: age, PBI affect. Mother; PBI control.Mother.

The second logistic regression that used the current depressive episode as the dependent variable found a statistically significant negative correlation with an affective maternal relationship. These findings suggest that an affective maternal relationship is a protective factor for the persistence of depressive symptoms after PPD. An odds ratio of less than 1.00 also indicates that women who had more affective mothers were less likely to have Major Depressive Disorder (Table 3).

\section{Discussion}

We studied a group at high risk for developing DD (i.e., women with a lower socioeconomic status who recently had a premature childbirth). The admission of a newborn in a neonatal unit imposes limitations and even privation on the mother-baby relationship. Generally, this situation is a potent stressor for both the mother and baby and may be a high-risk condition for the development of DDs (Yurdakull et al., 2009). We evaluated the participants for up to 1 year and more than 6 months after childbirth. We expected to find women who remained depressed after this period as a subgroup with persistent depressive symptoms that did not remit spontaneously because the women were not treated for their condition.

A CES-D cut-off point was used to define current DD, and an EPDS cut-off score was used as a retrospective evaluation of possible PPD. All of the patients who were currently depressed would likely have met the criteria for PPD, but the EPDS is not designed to be used retrospectively.

As expected, a high prevalence $(49.1 \%)$ of current DD was found in the high-risk group that had a low income, lack of social support, and the presence of a stressful event (i.e., premature delivery). For this specific subgroup of women, our initial hypothesis was confirmed. Depending on the quality of the motherdaughter bonding relationship (i.e., the patients' relationships with their mothers), women will develop resilience to or be at risk for the development of a DD when faced with adverse situations. Healthier (affective) relationships with their mother helped these women become more resilient and they did not develop a DD even when faced with a severe adverse stressor event.

Blatt and Homann (1992) showed that patterns of parental care that are either healthy or inadequate will be internalized by their children, representing either affective relationships or impaired mental representations that could lead to depression vulnerability in the future.

Preclinical studies in rats confirmed that the neonatal environment has a definite influence on animal development, inducing life-long behavioral, neuronal, and neuroendocrine alterations. Strong scientific evidenceindicates that stable mother-pup relationships are critical for normal development in rats (Azevedo, Souza, Donadio, Lucion, \& Giovenardi, 2010; Mello, Faria, Mello, Carpenter, Tyrka, \& Price, 2009).

The present results are consistent with theoretical concepts related to attachment that emphasize the value of maternal affect for the development of more resilient adults. Additionally, psychoanalytical studies have long emphasized the mother's role in the children's development of self-esteem and how they will adapt to the roles they play throughout life. Winnicott and Bogomoletz (2000) developed a theory that very early relationships will determine the adult's personality structure.

Mothers who overprotect, manipulate, or are affectless hinder the development of self-confidence and independence, generating emotionally fragile adults with fewer resources to manage traumatic and adverse situations (Handa et al., 2009). Even with our small sample and their specific characteristics, we were able to empirically confirm the powerful effect of maternal bonding on women's risk or resilience in the development of DDs when faced with adverse situations.

Limitations of the present study include small sample size and lack of generalizability to the general population because of the high-risk sample. A study with a larger sample of subjects selected from the community is needed to confirm the present results and to generalize the findings to the general population.

\section{Financial Disclosures:}

\section{Dr. Soares}

Grant/Research Support: Eli Lilly, AstraZeneca, Physicians Services Incorporated (PSI) Foundation, Allergen National Centre of Excellence, Hamilton Community Foundation, Wyeth Pharmaceuticals, Canadian Institute of Health Research (CIHR), National Alliance for Research on Schizophrenia and Depression (NARSAD) Foundation. 
Research Consultant: Wyeth, Eli Lilly, Bayer Healthcare Pharmaceuticals, Pfizer.

Speakers' Bureau: AstraZeneca, Wyeth, Eli Lilly, Pfizer, Lundbeck.

Advisory Boards: AstraZeneca, Wyeth, Eli Lilly, Bayer Healthcare Pharmaceuticals

\section{Dr. Mello}

Grant/Research Support: CNPq, FAPESP, Servier. Speakers' Bureau: Janssen Cillag, Roche, Eli Lilly, Pfizer.

Advisory Boards: GlaxoSmithkline, Eli Lilly, Pfizer.

\section{References}

Associação Brasileira de Empresas de Pesquisa (2003). Critério de classificação econômica Brasil.

Associação Brasileira de Empresas de Pesquisa (2007). Brazilian criteria of economicclasses (Critérios de Classes Econômicas Brasil). Brazilian Association of Research Enterprises (Associação Brasileira de Empresas de Pesquisa). http://www.abep.org/ codigosguias/CCEB2008-Base2006e2007.pdf; accessed May 14, 2012.

Azevedo, M. S., Souza, F. L., Donadio, M. V. F., Lucion, A. B., \& Giovenardi, M. (2010). Interventions in the neonatal environment in rats and their relationship to behavior in adulthood and maternal behavior. Psychology and Neuroscience, 3, 73-78.

Blatt, S. J., \& Homann, E. (1992). Parent-child interaction in the etiology of dependentand self-critical depression. Clinical Psychology Review, 12, 47-91.

Campos, R. C., Besser, A., \& Blatt, S.J. (2010). The mediating role of self-criticism and dependency in the association between perceptions of maternal caring and depressive symptoms. Depression and Anxiety, 27, 1149-1157.

Cox, J. L., Holden, J. M.,\& Sagovsky, R. (1987). Detection of postnatal depression:development of the 10-item Edinburgh Postnatal Depression Scale. British Journal of Psychiatry, 150, 782-786.

Enns, M. W., Cox, B. J., \& Clara, I. (2002). Parental bonding and adult psychopathology: Results from the US National Comorbidity Survey. Psychological Medicine, 32, 997-1008.

Fortuna, K., \& Roisman, G. I. (2008). Insecurity, stress, and symptoms of psychopathology: contrasting results from selfreports versus interviews of adult attachment. Attachment and Human Development, 10, 11-28.

Grotmol, K. S., Ekeberg, Ø., Finset, A., Gude, T., Moum, T., Vaglum, P., \& Tyssen, R. (2010). Parental bonding and self-esteem as predictors of severe depressive symptoms: A 10-year follow-up study of Norwegian physicians. Journal of Nervous and Mental Disease, 198, 22-27.

Handa, H., Ito, A., Tsuda, H., Ohsawa, I., \& Ogawa, T. (2009). Low level of parental bonding might be a risk factor among women with prolonged depression: A preliminary investigation. Psychiatry and Clinical Neurosciences, 63, 721-729.

Lima, A. R., Mello, M. F., \& Mari, J. J. (2010). The role of early parental bonding in the development of psychiatric symptoms in adulthood. Current Opinion in Psychiatry, 23, 383-387.
Mello, M. F., Faria, A. A., Mello, A. F., Carpenter, L. L., Tyrka, A. R., \& Price, L. H. (2009). [Childhood maltreatment and adult psychopathology: Pathways to hypothalamic-pituitaryadrenal axis dysfunction]. Revista Brasileira de Psiquiatria, 31, S41-S48.

Murray, C. J., \& Lopez, A. D. (1997). Global mortality, disability, and the contribution of risk factors: Global Burden of Disease Study. Lancet, 349, 1436-1442.

O'Connell, K. L. (2008). What can we learn? Adult outcomes in children of seriously mentally ill mothers. Journal of Child and Adolescent Psychiatric Nursing, 21, 89-104.

Parker, G. (1983). Parental overprotection: A risk factor in psychosocial development. New York: Grune \& Stratton.

Parker, G. (1989). The Parental Bonding Instrument: psychometric properties reviewed. Psychiatric Developments, 7, 317-335.

Parker, G., Hadzi-Pavlovic, D., Greenwald, S., \& Weissman, M. (1995). Low parental care as a risk factor to lifetime depression in a community sample. Journal of Affective Disorders, 33, 173180

R Development Core Team (2008). R: a language and environment for statistical computing. Vienna: R Foundation for Statistical Computing.

Radloff, L. S. (1977). The CES-D Scale: A self-report depression scale for research in the general population. Applied Psychological Measurement, 1, 385-401.

Restifo, K., Akse, J., Guzman, N. V., Benjamins, C., \& Dick, K. (2009). A pilot study of self-esteem as a mediator between family factors and depressive symptoms in young adult university students. Journal of Nervous and Mental Disease, 197, 166-171.

Rikhye, K., Tyrka, A. R., Kelly, M. M., Gagne, G. G, Jr., Mello, A. F., Mello, M. F., Price, L. H., \& Carpenter, L. L. (2008). Interplay between childhood maltreatment, parental bonding, and gender effects: Impact on quality of life. Child Abuse and Neglect, 32, 19-34

Ruschi, G., Sun, S. Y., Mattar, R., Chambô Filho, A, Zandonade, E, \& Lima, V. J. (2007). Aspectos epidemiológicos da depressão pósparto em amostra brasileira. Revista de Psiquiatria do Rio Grande do Sul, 29, 274-280.

Santos, I. S., Matijasevich, A., Tavares, B. F., Barros, A. J., Botelho, I. P., Lapolli, C., Magalhaes, P. V., Barbosa, A. P., \& Barros, F. C. (2007). Validation of the Edinburgh Postnatal Depression Scale (EPDS) in a sample of mothers from the 2004 Pelotas Birth Cohort Study. Cadernos de Saúde Pública, 23, 2577-2588.

Simone Hauck, S., Schestatsky, S., Terra, L., Knijnik, L., Sanchez, P., \& Ceitlin, L. H. F. (2006). Adaptação transcultural para o português brasileiro do Parental Bonding Instrument (PBI). Revista de Psiquiatria do Rio Grande do Sul, 28, 162-168.

Stansfeld, S., Head, J., Bartley, M., \& Fonagy, P. (2008). Social position, early deprivation and the development of attachment. Social Psychiatry and Psychiatric Epidemiology, 43, 516-526.

Ward, M. J., Lee, S. S., \& Polan, H. J. (2006). Attachment and psychopathology in a community sample. Attachment andHuman Development, 8, 327-340.

Winnicott, D. W., \& Bogomoletz, D. (2000). Desenvolvimento emocional primitivo (1945). Da Pediatria à psicanálise: Obras escolhidas. Rio de Janeiro: Imago.

Yurdakul, Z., Akman, I., Kuscu, M. K., Karabekiroglu, A., Yaylali, G., Demir, F., \& Ozek, E. (2009). Maternal psychological problems associated with neonatal intensive care admission. International Journal of Pediatrics, 2009, 591359. 
